\title{
Effects of extreme temperatures on cerebrovascular mortality in Lisbon: a distributed lag non-linear model
}

\author{
Mónica Rodrigues ${ }^{1} \cdot$ Paula Santana ${ }^{1} \cdot$ Alfredo Rocha $^{2}$ \\ Received: 6 October 2018 / Revised: 31 December 2018 / Accepted: 28 January 2019 / Published online: 23 February 2019 \\ (C) ISB 2019
}

\begin{abstract}
Cerebrovascular diseases are the leading cause of mortality in Portugal, especially when related with extreme temperatures. This study highlights the impacts of the exposure-response relationship or lagged effect of low and high temperatures on cerebrovascular mortality, which can be important to reduce the health burden from cerebrovascular diseases. The purpose of this study was to assess the effects of weather on cerebrovascular mortality, measured by ambient temperature in the District of Lisbon, Portugal. A quasi-Poisson generalized additive model combined with a distributed lag non-linear model was applied to estimate the delayed effects of temperature on cerebrovascular mortality up to 30 days. With reference to minimum mortality temperature threshold of $22{ }^{\circ} \mathrm{C}$, there was a severe risk $(\mathrm{RR}=2.09,95 \% \mathrm{CI} 1.74,2.51)$ of mortality for a 30-day-cumulative exposure to extreme cold temperatures of $7.3{ }^{\circ} \mathrm{C}$ (1st percentile). Similarly, the cumulative effect of a 30-day exposure to an extreme hot temperature of $30{ }^{\circ} \mathrm{C}$ (99th percentile) was $52 \%(\mathrm{RR}=1.65,95 \% \mathrm{CI} 1.37,1.98)$ higher than same-day exposure. Over the 13 years of study, non-linear effects of temperature on mortality were identified, and the probability of dying from cerebrovascular disease in Lisbon was $7 \%$ higher in the winter than in the summer. The findings of this study provide a baseline for future public health prevention programs on weather-related mortality.
\end{abstract}

Keywords Cerebrovascular diseases · Extreme temperatures $\cdot$ Lag effects $\cdot$ Distributed lag non-linear model (DLNM) · Portugal

\section{Introduction}

Several epidemiological studies have provided evidence for the association between ambient temperature and mortality rate (Åström et al. 2013; Gasparrini et al. 2015a). The findings of these studies are similar. Generally, the relationship between temperature and mortality was U-, J- or V-shaped, defined by a temperature range of minimum mortality and monotonically increasing incidence for colder and warmer temperatures (Davis et al. 2016; Schwartz et al. 1996).

Electronic supplementary material The online version of this article (https://doi.org/10.1007/s00484-019-01685-2) contains supplementary material, which is available to authorized users.

Mónica Rodrigues

monica.a.rodrigues@hotmail.com

1 Centre of Studies on Geography and Spatial Planning, Department of Geography and Tourism, University of Coimbra, Coimbra, Portugal

2 Centre for Environmental and Marine Studies, Department of Physics, University of Aveiro, Aveiro, Portugal
When the temperature is below or above a certain critical threshold, mortality gradually increases as the temperature is decreased or increased (Anderson and Bell 2009; Näyhä 2005). The location of the minimum function, called the minimum mortality threshold, may be an indicator of adaptive capacity or acclimatization (Kendrovski 2006). Minimum mortality thresholds were reported in other studies in Spain (Näyhä 2005), the USA (Patz et al. 2010), and in Russia (Curriero et al. 2002).

The mortality rates during winter (Antunes et al. 2017; Keating and Donaldson 1997; Vasconcelos et al. 2013) and in summer season (Braga et al. 2001; Gasparrini et al. 2015b; Pattenden et al. 2003) reflect the significant impact of seasonal factors on certain causes of death, particularly cardiovascular diseases (Eng and Mercer 1998) and cerebrovascular diseases (Kendrovski 2006). The Eurowinter Group (Keating and Donaldson 1997) found smaller increases in cold mortality in northern Finland (cold region) than in warmer regions. In all these studies, a variety of models have been used to assess the impacts of temperature on mortality, such as time-series (Braga et al. 2001; Gasparrini et al. 2015b; Keating and Donaldson 1997). 
Extreme temperatures have a lag effect on cerebrovascular mortality (Anderson and Bell 2009), and in time series analyses, a popular approach is based on distributed lag models (DLMs) (Dominici et al. 2000), generalized to distribute lag non-linear models (DLNMs) (Armstrong 2006) when including non-linear exposure-response associations. The distributed lag non-linear model was developed to simultaneously estimate the non-linear and delayed effects of temperature on mortality (Gasparrini et al. 2010).

The lagged effects of extreme temperatures on mortality have been reported in many regions, including Europe, Australia, China, Canada, and the USA (Anderson and Bell 2009; Armstrong 2006; Åström et al. 2013). In Portugal, very few studies (Antunes et al. 2017) have examined the shortterm and delayed effects of ambient temperature on mortality. No previous study has analyzed the time lag and the impact of both low and high temperature effects on cerebrovascular mortality in the District of Lisbon. Our study is the first to provide epidemiological evidence in Portugal.

The goals of this study were (i) to assess the associations between extreme temperature exposure and mortality from cerebrovascular diseases, (ii) to compare these associations in cold and hot seasons, and (iii) to evaluate the lag effects and temperature thresholds in the District of Lisbon, Portugal.

\section{Materials and methods}

\section{Data collection}

We requested data on daily counts of deaths from cerebrovascular diseases as well as meteorological data and concentrations of air pollutants from 1 January 2000 to 31 December 2013. The geographical area under study comprises the District of Lisbon, Portugal.

The data of cerebrovascular mortality (CBM) were provided by Statistics Portugal. The cause-specific mortality was classified according to the International Classification of Diseases, 10th Revision: Cerebrovascular diseases (ICD-10: I60-I69).

Daily meteorological data, including ambient temperature measures (daily mean temperature, daily maximum temperature, daily minimum temperature) and dew point were collected from the National Climatic Data Center for the Geofísico Meteorological Station. Temperature measurements in degrees Kelvin $(\mathrm{K})$ were converted to degrees Celsius $\left({ }^{\circ} \mathrm{C}\right)$. We calculated the relative humidity ( $\mathrm{HR}, \%)$ using formula published previously (Lawrence 2005).

Daily air pollution data on particulate matter less than $10-\mu \mathrm{m}$ aerodynamic diameter $\left(\mathrm{PM}_{10}\right)$ were obtained from the Portuguese Environment Agency. Concentrations of $\mathrm{PM}_{10}$ were measured and recorded hourly at each station. The daily average values of $\mathrm{PM}_{10}$ concentrations were calculated for urban background monitoring stations in the study area.

\section{Statistical methods}

All the analysis was based on generalized additive models (GAM). Initially, we performed univariate analysis to assess the association between cerebrovascular mortality (CBM) and each risk factor individually Furthermore, multivariable GAM models will be explored such that covariates will be included based on their relative contributions in the univariate analyses in the following way:

1. Covariates with correlation coefficients $|r|>0.7$ will be excluded from the models to avoid issues related to multicollinearity.

2. Covariate inclusion from univariate analysis will be based on a $p$ value smaller than 0.1 .

3. Inference is based on the $5 \%$ level of significance.

4. The final model fit will be assessed using modified Akaike information criteria for models with overdispersed data Quasi-AIC (Gasparrini et al. 2010).

The final step of the time series model is to construct models based on data from (1) the entire year, (2) the summer period only (June, July, August, and September), and (3) the winter period only (December, January, February, and March).

The usual practice is to assume an overdispersed Poisson regression model for the mortality counts. Quasi-Poisson has been used in several weather exposure-mortality studies (Armstrong 2006; Gasparrini et al. 2015a,b; Schwartz et al. 1996). In this study, we applied quasi-Poisson generalized additive models, with smooth terms fitted by penalized splines to estimate the association between daily mortality daily counts from CBM on day $t, Y_{t}, t=1, \ldots, n$ and several covariates. Following Gasparrini et al., (2010), the general form of the model is given by:

$g\left(\mu_{t}\right)=\alpha+\sum_{j=1}^{J} s_{j}\left(x_{t j} ; \beta_{j}\right)+\sum_{k=1}^{K} \gamma_{k} u_{t k}$,

where $\mu_{t} \equiv E(Y)$ and $g$ is a monotonic link function. The functions $s_{j}$ denotes the smooth function for variables $x_{j}$ while $\gamma_{k}$ is the parameter estimate for the linear relationship of variables, $u_{k}$ and $g\left(\mu_{t}\right)$. The following covariates were considered in the model: ambient temperature (tmin, tmax, tmean), relative humidity (HR), and dew point (DEWP) with other confounding variables such as day of the week (DOW) a binary indicator for weekend or weekday, holiday period (HOY), daily $\mathrm{PM}_{10}$ values $\left(\mathrm{PM}_{10}\right)$, and season (winter, spring, autumn, and summer). 
Table 1 Descriptive statistics for meteorological measures, air pollutants, and cerebrovascular mortality (CBM). District of Lisbon (Portugal), period 20002013

\begin{tabular}{|c|c|c|c|c|c|c|c|}
\hline \multirow[t]{2}{*}{ Variables } & \multirow[t]{2}{*}{ Mean } & \multirow[t]{2}{*}{ SD } & \multirow[t]{2}{*}{ Min } & \multicolumn{3}{|c|}{ Percentiles } & \multirow[t]{2}{*}{ Max } \\
\hline & & & & 25 th & 50 th & 75 th & \\
\hline \multicolumn{8}{|l|}{ Temperature $\left({ }^{\circ} \mathrm{C}\right)$} \\
\hline Tmean & 17.38 & 5.19 & 4.10 & 13.30 & 17.00 & 21.43 & 33.30 \\
\hline Tmin & 9.07 & 2.80 & 0.10 & 7.10 & 9.30 & 11.10 & 17.80 \\
\hline Tmax & 15.75 & 3.17 & 7.30 & 13.90 & 15.60 & 17.20 & 50.70 \\
\hline Relative humidity (\%) & 66.81 & 18.63 & 26.70 & 57.40 & 69.70 & 80.90 & 102.60 \\
\hline $\mathrm{PM}_{10}\left(\mu \mathrm{g} / \mathrm{m}^{3}\right)$ & 36.53 & 21.04 & 4.50 & 21.40 & 31.35 & 46.00 & 241.60 \\
\hline Dew point $\left({ }^{\circ} \mathrm{C}\right)$ & 10.75 & 4.12 & -1.52 & 8.10 & 11.20 & 13.90 & 20.40 \\
\hline $\mathrm{CBM}$ & 8.56 & 3.49 & 2.00 & 6.00 & 8.00 & 11.00 & 28.00 \\
\hline
\end{tabular}

$S D$ standard deviation, Min minimum, Max maximum; $P M_{10}$ particulate matter less than $10 \mu \mathrm{m}$ aerodynamic diameter
Oftentimes, the effect of a specific exposure event is not limited to the period when it is observed, but it is delayed in time (Gasparrini et al. 2010). Inference about the effect of unit increase in the climatic variable on a single day is not reasonable; the effect of climatic variable has been found to spread over several days (Braga et al. 2001; Gasparrini et al. 2010; Keating and Donaldson 1997; Pattenden et al. 2003). Specifically, the association between mortality from CBM and temperature exposure may take more than a few days to manifest itself.

The model formulation is as follows:

$$
\begin{aligned}
\log \left[E\left(Y_{t}\right)\right] & =\alpha+\operatorname{cb}\left(\text { temperature }_{t}, \ldots, \text { temperature }_{t-l}\right) \\
& +s(\mathrm{PM} 10)+s(\mathrm{RH})+s(\mathrm{DEWP})+s(\text { Time }) \\
& +\delta_{1 j} \mathrm{DOW}_{t}+\delta_{2 j} \mathrm{HOY}_{t}+\delta_{3 j} \text { Season }_{t}+\delta_{4 j} \text { Year }_{t}
\end{aligned}
$$

Specifically, $s$ (Time) was fitted with 13 degrees of freedom (dfs) per year of the study as natural cubic spline function to control for long-term temporal trend and seasonality in the data. The number of df determines the smoothness, and the more degrees of freedom, the more flexibility is allowed in the shape of the function (Dominici et al. 2000; Pattenden et al. 2003). Different choices of df were explored, see Table S1. Similarly, $s\left(\mathrm{PM}_{10}\right), s(\mathrm{RH})$, and $s(\mathrm{DEWP})$, represent the natural cubic spline functions for $\mathrm{PM}_{10}$, RH, and DEWP respectively, with two df for each. Season is a fixed categorical variable in the model not a smooth function to allow the comparison between seasons while a linear term for Year, HOY, and DOW as an indicator of day of the week was included in the model.

Temperature is the main exposure of interest. Previous studies have used a lag of 30 days (Antunes et al. 2017; Yu et al. 2011). In this study, lagged temperature was evaluated for lags between 0 and 30 days.

The term "cb (Temperature, lag)" represents the crossbasis matrix obtained by applying to temperature lag- response-exposure. The non-linear and delayed exposurelag-response relationship between temperature and CBM mortality was modeled by applying a bi-dimensional cross-basis spline function describing simultaneously the dependency of the relationship along the temperature range and its distributed lag effects.

The cross-basis parameterization for the exposure-lagresponse function can be re-expressed as:

$s(x, t)=w_{x, t}^{T} \eta=\sum_{l=l_{0}}^{L} f \cdot \omega\left(x_{t-l}, l\right)$

The bi-dimensional function is $f . \omega\left(x_{t-l}, l\right)$ where $f(x)$ and $\omega(l)$ represent the smooth function for exposure-response and lag-response function. Is defined as the exposure-lag-response function, and models simultaneously the exposure-response curve along temperature and lag-response curve namely an exposure-lag-response surface (Gasparrini 2014). Quadratic B-splines were used for both temperature-response function, $f(x)$ and lag-response function, $\omega(l)$ with several 3 knots placed at equally spaced positions.

The model selection for the number of knots and $\mathrm{df}$ is based on modified Akaike information criteria for models with overdispersed data Quasi-AIC (Gasparrini et al. 2010). See the appendix Table S1 for the different formulation of the 128 candidate models including models for lags $0-35$ days.

All statistical analyses were performed with R 3.4.0 (The R Project for Statistical Computing, http://www.r-project.org), with the package "dlnm" to create the DLNM.

\section{Results}

\section{Exploratory data analysis}

Summary statistics for meteorological measures, air pollutants, and cerebrovascular mortality (CBM) were presented 
Table 2 Summary of univariate DLNM GAMs fitted to cerebrovascular mortality (CBM) lags days (0-30). District of Lisbon (Portugal), period 2000-2013

\begin{tabular}{lccc}
\hline Model & $p$ value & $R$-sq adj & RMEL \\
\hline CBM $\sim$ tmean & $<0.0001$ & 0.07 & 3197.3 \\
CBM $\sim$ season & $<0.0001$ & 0.10 & 3103.2 \\
CBM DEWP & $<0.0001$ & 0.05 & 3242.9 \\
CBM $\sim$ HR & $<0.0001$ & 0.01 & 3344.9 \\
CBM $\sim \mathrm{PM}_{10}$ & $<0.0001$ & 0.02 & 3326.9 \\
CBM DOW & 0.538 & -0.0001 & 3367.9 \\
CBM Hoy & 0.324 & $\sim 0$ & 3366.6 \\
CBM Year & $<0.0001$ & 0.03 & 2999.8 \\
\hline
\end{tabular}

Inclusion criterion into the multivariable GAMs is based on $p$ values $\leq$ 0.1. $R$-sq adj adjusted R-squared, $R M E L$ restricted maximum likelihood

in Table 1. During the study period, the average of daily mean temperatures (tmean), $\mathrm{PM}_{10}$, relative humidity, dew point, and number of deaths were $17.38{ }^{\circ} \mathrm{C}, 36.53 \mu \mathrm{g} / \mathrm{m}^{3}, 66.81 \%$, $10.75^{\circ} \mathrm{C}$, and 8.56 , respectively.

The number of deaths was highest in the winter and lowest in the summer. Furthermore, the average (standard deviation) of mean daily temperature across Lisbon during the period 2000 to 2013 ranges between mean $(\mathrm{SD})=16.97(4.96)$ and mean $(\mathrm{SD})=17.94(4.96)$.

\section{Modeling approach}

The cerebrovascular mortality (CBM) data was fitted using distributed non-linear model (DNLM) and generalized additive model (GAM) (Armstrong 2006); a quasi-Poisson link function was to account for over-dispersion in the counts data.

Based on the exploratory data analysis (EDA) on the correlation among the meteorological variables, temperature variables (tmax, tmin) were not used in the multivariable analysis due to multicollinearity. Only mean daily temperature was used (tmean). Usually thresholds of correlation coefficients between predictor variables of $|r|>0.7$ is an appropriate indicator for when collinearity begins to severely distort model estimation and subsequent prediction (Dormann et al. 2013).

Similarly, Table 2 presents the univariate DLNM GAM models and their respective inclusion. The inclusion criteria used is based on a $p$ value of at least 0.1 ; therefore, the variable "HOY" indicating holiday will not be included in the multivariable model. Similarly, the day of the week "DOW" was not significantly associated with CBM. Hence, "DOW" will not be included in the multivariable model fitting for CBM.

The best fitted model for temperature-mortality association for all year round according to QAIC is Model 1 with lag 0-30 (Table S1). This model described the mean daily temperature delayed effects (lag 0-30) by quadratic B-spline function for exposure-response and lag-response with a total $\mathrm{df}$ of 30 and 3 knots placed at equal distance, respectively. The model also
Fig. 1 Contributions of the model terms the temperaturecerebrovascular mortality association. a Season. b Smooth term in dew point. c Smooth in relative humidity. d Smooth term in PM10. The dashed curves represent the $95 \%$ confidence interval for the fitted curves. The reference temperature was at minimum mortality temperature of $22{ }^{\circ} \mathrm{C}$
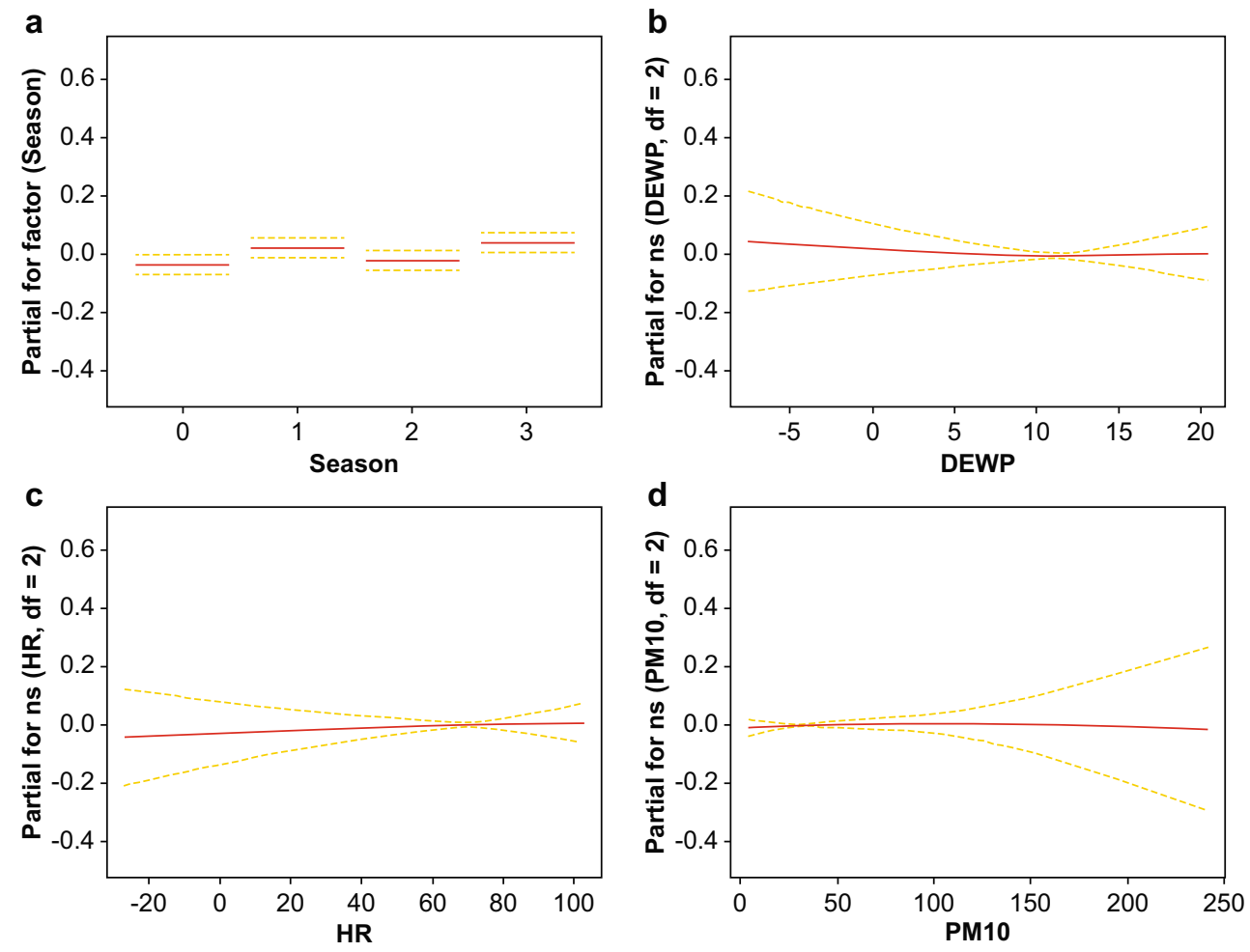

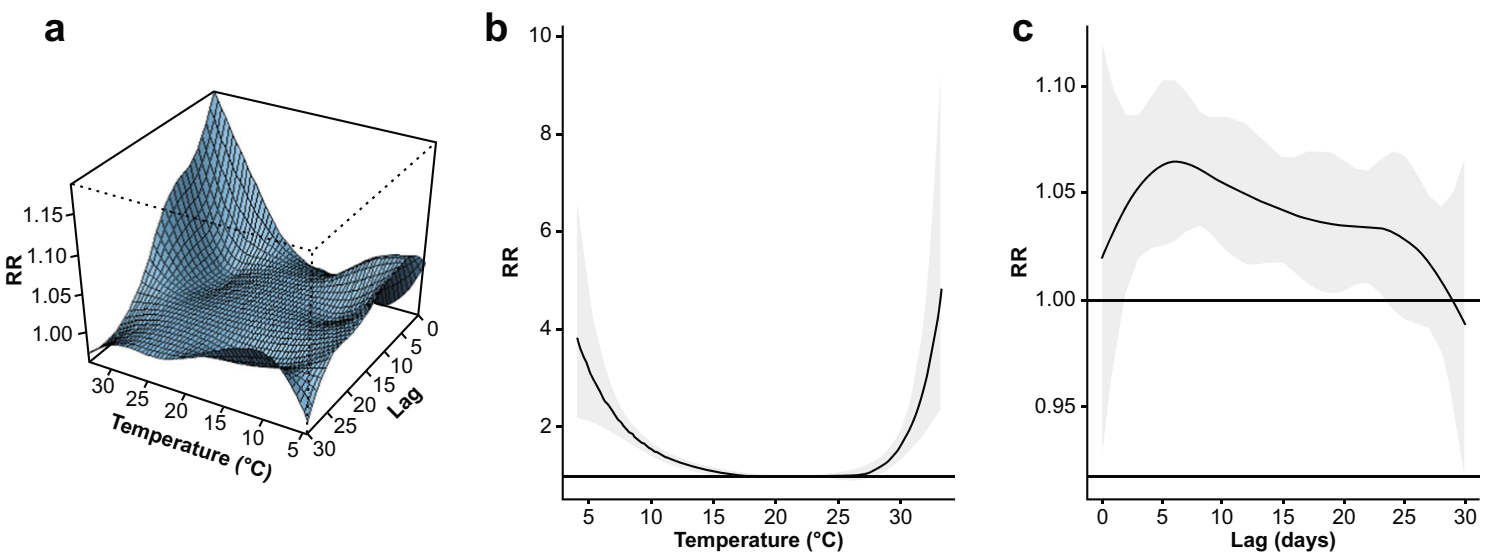

Fig. 2 Cumulative effects of mean temperature $\left({ }^{\circ} \mathrm{C}\right)$ on cerebrovascular mortality (CBM) for the entire year for the District of Lisbon, Portugal, 2000-2013. a The relative risk (RR) of mortality dependence on temperature and lag days using cross-basis smoothing by natural splines. b Estimated relative risk for the effect of temperature on mortality. c

includes the term "Time" described by a natural cubic spline function to control for long-term temporal trend and seasonality with $13 \mathrm{df}$ generated per year of study and natural cubic spline for $\mathrm{PM}_{10}, \mathrm{RH}$, and DEWP respectively, with $2 \mathrm{df}$ each, while Season and Year are fixed categorical variables.

Fig. 1 displays the contributions of the model terms (Season, relative humidity, dew point, and $\mathrm{PM}_{10}$ ) to the temperature-cerebrovascular mortality association for the best fitted model described above. The flattening of the estimated association shown in Fig. $1 \mathrm{~b}$ to $\mathrm{d}$ indicates there is no clear trend observed in CBM with dew point, relative humidity, and $\mathrm{PM}_{10}$, respectively. We can see in Fig. 1a that there is significant increase in the risk of mortality from cerebrovascular disease in winter ( $\mathrm{RR}=1.06,95 \% \mathrm{CI} 1.00-1.13)$ and autumn $(\mathrm{RR}=1.08,95 \% \mathrm{CI} 1.03-1.13)$ compared to the risk of CBM in the summer period.
Estimated temperature effect $\left(5^{\circ} \mathrm{C}\right)$ on mortality at various lag days $(0$ 30). The line represents the relative risks while the gray shaded regions indicate the $95 \%$ confidence intervals. The reference temperature was at minimum mortality temperature of $22{ }^{\circ} \mathrm{C}$

The analyses focused more on the relationships of the lagged temperature metrics and mortality. The strength of these relationships varied depending on the temperature value and whether the mortality was recorded on the same day of exposure or after a few days. The idea of cumulative effect of temperature is to sum up the effects of all contributions of the exposure to the maximum lag indicated. Considering the cumulative effect of temperature on CBM at different lags (see Fig. 2), there is a slow and short adverse effect of low temperature $\left(\leq 5^{\circ} \mathrm{C}\right)$ peaking at peak at 6-day lag (RR $1.065,95 \% \mathrm{CI}$ $1.028-1.103)$. As presented in Fig. 2b, the cumulative effect (lag 0-30) of exposure to minimum temperature of $4.1{ }^{\circ} \mathrm{C}$ is $3.81(95 \%$ CI $2.19 ; 6.61)$ while the cumulative exposure to maximum temperature of $33.3{ }^{\circ} \mathrm{C}$ is 4.85 (95\% CI $\left.2.39 ; 9.85\right)$. The short adverse effect at a temperature of $5^{\circ} \mathrm{C}$ is displayed in the right graph in Fig. 2c. The middle graph shows a similar a

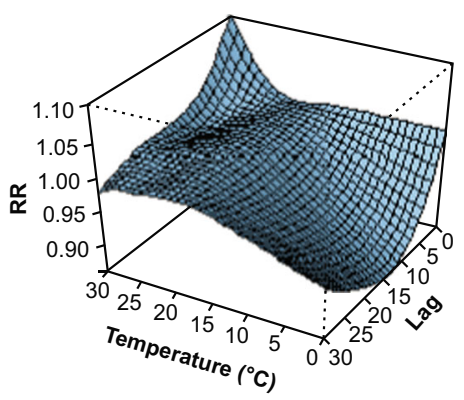

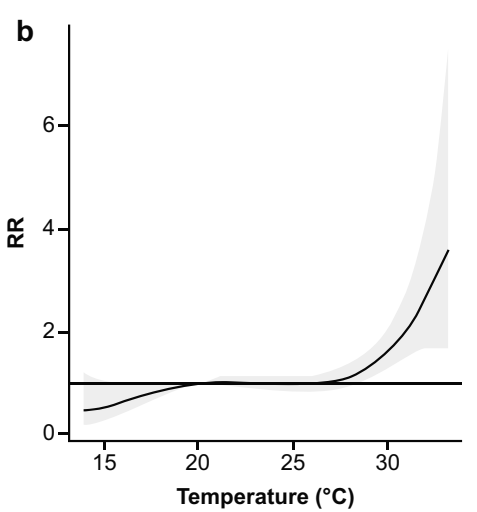

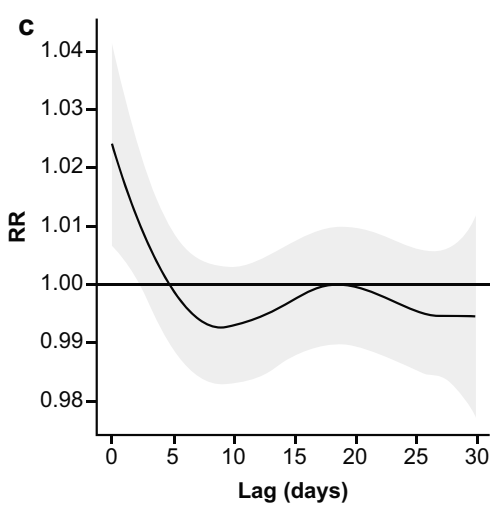

Fig. 3 Effects of mean temperature $\left({ }^{\circ} \mathrm{C}\right)$ on cerebrovascular mortality (CBM) during summer months (June-September) for the District of Lisbon, Portugal, 2000-2013. a Relative risk (RR) of mortality by temperature and lag days using cross-basis smoothing by natural splines. b Estimated relative risk for the effect of temperature on mortality. c
Estimated temperature effect on mortality at various lag days (0-30) at 99th percentile value of $30^{\circ} \mathrm{C}$. The line represents the relative risks while the gray shaded regions indicate the $95 \%$ confidence intervals. The reference temperature was at minimum mortality temperature of $22.5^{\circ} \mathrm{C}$ 

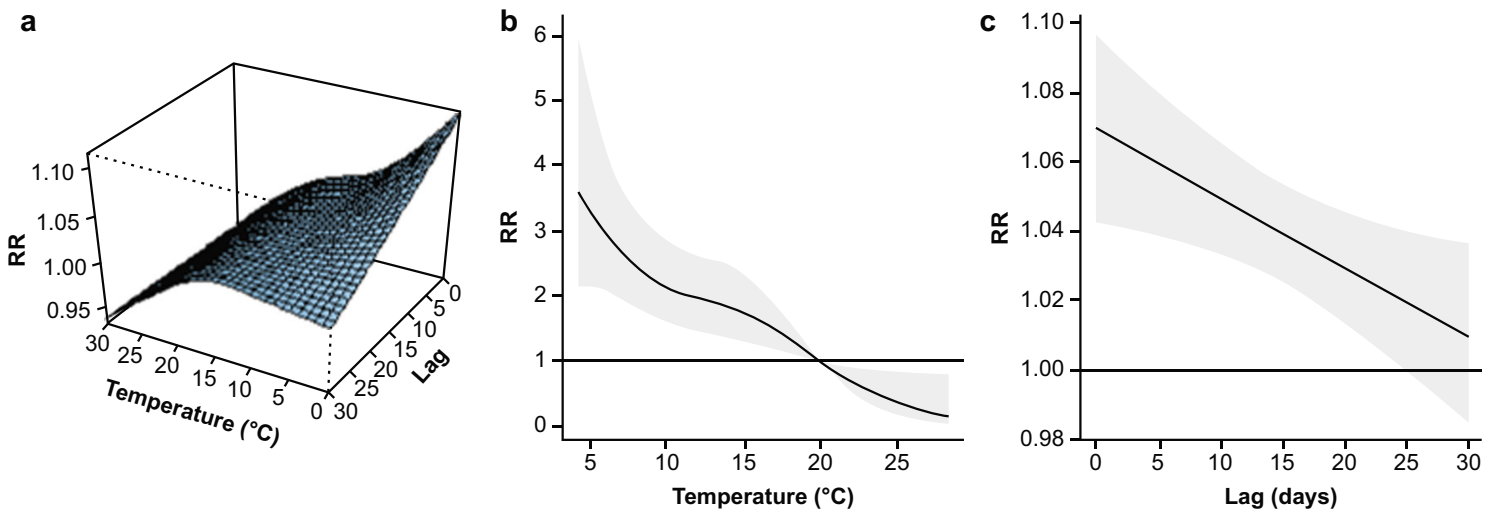

Fig. 4 Effects of mean temperature $\left({ }^{\circ} \mathrm{C}\right)$ on cerebrovascular mortality (CBM) during the winter months (December-March) for the District of Lisbon, Portugal, 2000-2013. a Relative risk (RR) of mortality by temperature and lag days using cross-basis smoothing by natural splines. $\mathbf{b}$ Estimated relative risk for the effect of temperature on mortality. c

pattern with a slight increase in risk of CBM at temperatures above $25^{\circ} \mathrm{C}$.

Considering the summer data, most of the explanatory variables are not associated with CBM. The significant association between temperature and CBM is depicted in Fig. 3. Figures $3 \mathrm{~b}$ and $\mathrm{c}$ show the effect of temperature on mortality risk. It indicated that the mortality risk increases above a temperature of approximately $27^{\circ} \mathrm{C}$, and the effect is immediate after exposure in the summer months (lag 0 ).

Similar to the data collected for the entire year, for winter months, the relative risk of CBM decreases over the years by a factor of -0.007 . The relationship between mortality risk and temperature for different lags is displayed in Fig. 4. The effect of temperature on mortality risks is highest on the same day (lag 0 ) and at temperatures lower than $5^{\circ} \mathrm{C}$ while mortality risks decline steadily thereafter (Fig. 4, middle graph).

Figure 5 presents the evaluation of the effect of hot and cold temperatures on cause-specific mortality as well as lagmortality risk relationships specific to hot and cold temperatures. Displayed in Fig. 5 is the effect of high temperature at the 99th percentile $\left(30.0^{\circ} \mathrm{C}\right)$ and other percentiles, such as the 75th percentile of temperature $21.4^{\circ} \mathrm{C}$. Similarly, the effect of cold temperatures at the 1 st percentile $\left(7.3^{\circ} \mathrm{C}\right)$ as well as the 25th percentile of temperature at $13.3{ }^{\circ} \mathrm{C}$ on mortality risk from cerebrovascular along the lag days was also displayed in Fig. 5. Both extreme hot and cold temperatures are associated with a higher risk of CBM, and the effect is immediate (highest at lag 0 for hot temperatures and lag 6 for cold temperatures) (Fig. 5a, b). Since the effect extreme temperature is immediate, the temperature thresholds were examined at lag 0 . The thresholds for cold temperature stand around $17^{\circ} \mathrm{C}$ and at $21^{\circ} \mathrm{C}$ for hot temperatures for CBM risk (Fig. 5).

Table 3 presents the lag-cerebrovascular cumulative relative risks of cold and hot temperature effects at 1 st, 25 th, 75 th, and 99th percentile of temperatures together with their $95 \%$ confidence intervals (with reference to MMT of $22{ }^{\circ} \mathrm{C}$ ).
Estimated temperature effect on mortality at various lag days $(0-30)$ at 1 st percentile value of $7.3^{\circ} \mathrm{C}$. The line represents the relative risks while the gray shaded regions indicate the $95 \%$ confidence intervals. The reference temperature was at minimum mortality temperature of $20^{\circ} \mathrm{C}$

Varying temperature percentiles were evaluated: high temperature was evaluated at 99 th percentile $\left(30.0^{\circ} \mathrm{C}\right)$, 75 th percentile $\left(21.4^{\circ} \mathrm{C}\right)$ while the cold effect was evaluated at 1 st percentile $\left(7.3^{\circ} \mathrm{C}\right)$ and 25 th percentile $\left(13.3^{\circ} \mathrm{C}\right)$ with reference at minimum mortality temperature (MMT) of $22^{\circ} \mathrm{C}$.

The cumulative effect of temperature is obtained by summing the effects of all contributions of the exposure up to the maximum lag indicated. For example, the relative risks of the cumulative effects for $7.3{ }^{\circ} \mathrm{C}$ over the same day, 6 days and 30 days of exposure are $0.97,1.21$, and 2.09 (Table 3), respectively, with reference to MMT. This implies that there is severe risk $(\mathrm{RR}=2.09,95 \% \mathrm{CI} 1.74 ; 2.51)$ of CBM for 30 days cumulative exposure at cold temperature of $7.3^{\circ} \mathrm{C}$. The cumulative exposure of the middle 50th percentile temperature (25th percentile, $13.3{ }^{\circ} \mathrm{C}$ and 75 th percentile, $21.4{ }^{\circ} \mathrm{C}$ ) is very low (see Table 3 and Fig. 5a, b). Similarly, the cumulative effect of 30 days of exposure to temperature of $30.0^{\circ} \mathrm{C}$ is about $52 \%$ higher than the same day exposure.

\section{Assessment of models}

For comparison and assessment of knots, df, and delay effects, we fitted several models with lags $0-35$. Comparing the model fitted delayed effect lags 0-30, models with lags 0-35 performed better with lower QAIC in each category (Table S1). However, differences in the estimated temperature-mortality association are relatively similar.

The best fitted model (in category 0-35 lags) for temperature-mortality association for the whole year round according to QAIC (model 1 with lags $0-35$ in Table S1), described mean daily temperature delayed effects by quadratic $\mathrm{B}$-spline function for exposure-response and lag-response with a total df of 30 and 3 knots placed at equal distance, respectively, year by a natural cubic spline function to control for long-term temporal trend and seasonality with $13 \mathrm{df}$ generated per year of study. 
Fig. 5 Lagged relationship between cerebrovascular mortality $(\mathrm{CBM})$ risk curves and mean temperature $\left({ }^{\circ} \mathrm{C}\right)$ for the District of Lisbon, Portugal, 2000-2013. a, b Cold temperatures (minimum, 1 st and 25th percentile, median) and high temperatures (median, 75th and 99th percentile, maximum). c, d Mortality risks at specific lags (lag 0 and lag 6) and at 1st, 25th, 75th, and 99th percentile temperatures of $7.3^{\circ} \mathrm{C}, 13.3^{\circ} \mathrm{C}, 21.4^{\circ} \mathrm{C}$, and $30.0^{\circ} \mathrm{C}$, respectively, with reference temperature set at minimum mortality temperature of $22{ }^{\circ} \mathrm{C}$
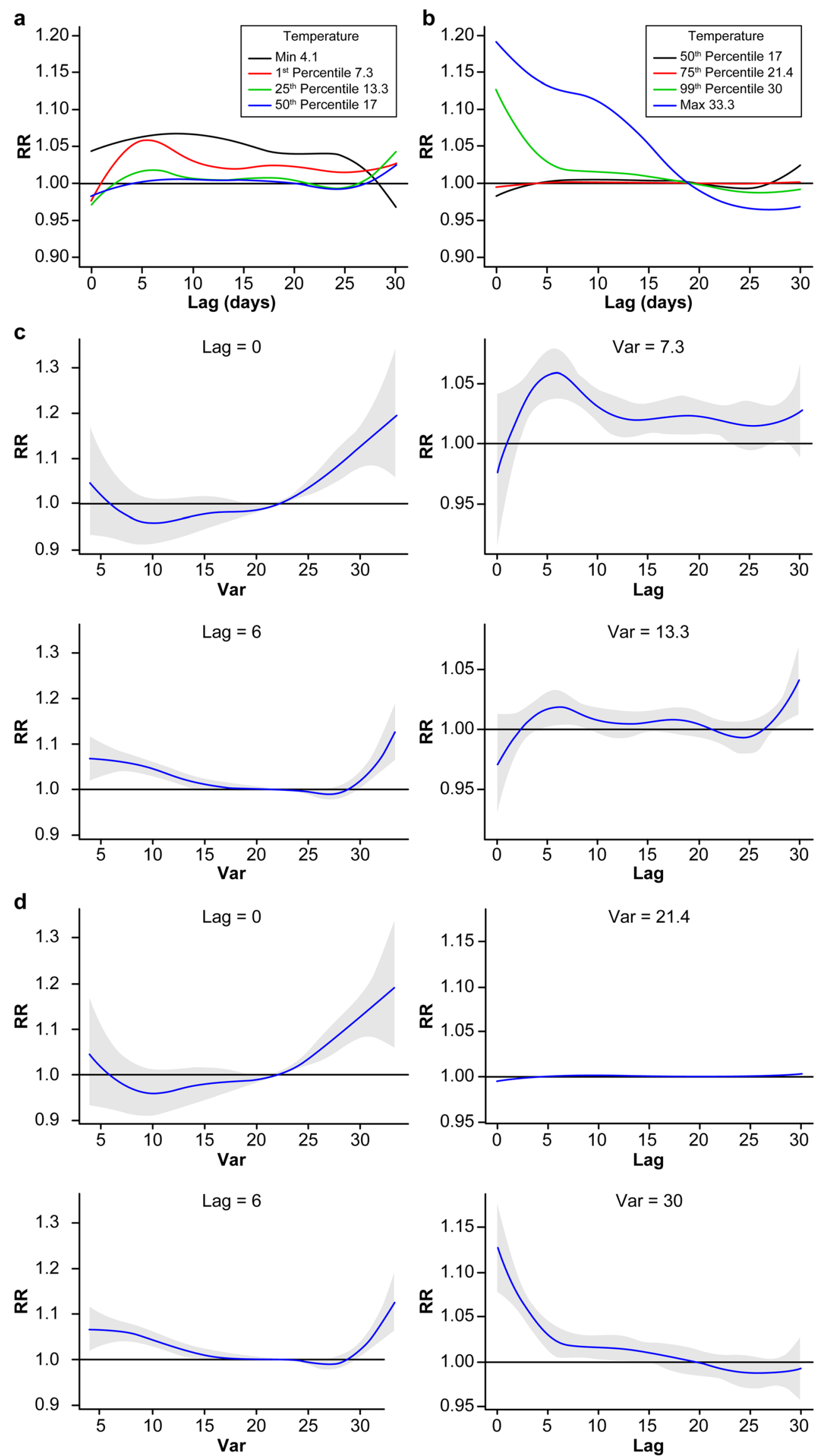
Table 3 Lag-cerebrovascular relative risk (RR) (with 95\% confidence interval, $95 \% \mathrm{CI}$ ) of cold and hot temperature effects at 1st, 25th, 75th, and 99th percentile of temperatures. District of Lisbon (Portugal), period 2000-2013 (with reference at MMT of $22{ }^{\circ} \mathrm{C}$ )

\begin{tabular}{llll}
\hline Temperature & $\begin{array}{l}\text { Lag 0 } \\
\text { RR }(95 \% \mathrm{CI})\end{array}$ & $\begin{array}{l}\text { Lag 6 } \\
\text { RR }(95 \% \mathrm{CI})\end{array}$ & $\begin{array}{l}\text { Lag 30 } \\
\text { RR }(95 \% \mathrm{CI})\end{array}$ \\
\hline $7.3{ }^{\circ} \mathrm{C}$ & $0.97(0.91 ; 1.03)$ & $1.21(1.05 ; 1.38)$ & $2.09(1.74 ; 2.51)$ \\
$13.3{ }^{\circ} \mathrm{C}$ & $0.97(0.92 ; 1.01)$ & $0.99(0.90 ; 1.08)$ & $1.18(1.07 ; 1.31)$ \\
$21.4{ }^{\circ} \mathrm{C}$ & $0.99(0.99 ; 1.00)$ & $0.99(0.98 ; 1.00)$ & $1.00(0.99 ; 1.01)$ \\
$30.0{ }^{\circ} \mathrm{C}$ & $1.13(1.08 ; 1.18)$ & $1.55(1.40 ; 1.71)$ & $1.65(1.37 ; 1.98)$ \\
\hline
\end{tabular}

We present exposure-response and lag-response curves for models 1 (0-30 lags and 0-35 lags) and models 6 (0-30 lags and $0-35$ lags) in Fig. 6. The left panel reported the cumulative mortality risk for different model specifications while the right panel displayed the estimated contributions to the risk associated with morality from $\mathrm{CBM}$ at each lag at $5{ }^{\circ} \mathrm{C}$ temperature exposure. Model 1 with 0-35 lags predicts a maximum increase in risk at lag 10, with RR of $1.055(95 \% \mathrm{CI}$ 1.031-1.079) compared with RR of 1.055 (95\% CI 1.0251.027) estimated from similar model (model 1) with 0-30 lags at peak at lag 6 (RR 1.065, 95\% CI 1.028-1.103). All models explored suggest a significant decrease in risk at longer lags.

\section{Discussion}

Our study compared the relationships between temperature and mortality resulting from cerebrovascular diseases in hot and cold weather conditions. To the best of our knowledge, this is the first study to assess potentially significant associations between temperature and cerebrovascular mortality and to quantify the lagged effects in Portugal. The effects of temperature on daily mortality were investigated for the winter and the summer seasons. Mean temperature was thus selected as a temperature indicator to study the relationship between weather and mortality. Moreover, this indicator was selected in other studies carried out in China, Australia, and the USA (Guo et al. 2011; Yu et al. 2010). It has also been reported that the selection of correct variable is essential because some humidity measures can be highly correlated with other atmospheric variables, making it difficult to identify the unique contribution of any single variable (Davis et al. 2016). For example, in the study by Vajanapoom et al. (2001), they excluded dew point and mean temperature from their model because of their high variance inflation factor values. Also, Dormann et al. (2013) stated that they do not think the problem of collinearity can be solved, for logical reasons: without mechanistic ecological understanding, collinear variables cannot be separated by only statistical means.

In this study, we used a distributed lag non-linear model to assess the lag effects of temperature on cerebrovascular mortality. The lag structures of both hot and cold temperatures effects were investigated for 30 days. Previous studies have suggested that short time lags cannot completely capture the effects of temperature on cerebrovascular mortality (Anderson and Bell 2009; Goodman et al. 2004); longer time lags should therefore be applied to examine the effects of temperature (Schwartz et al. 1996). In this study, we observed increased risk of extreme -cold and -heat temperatures on CBM at shorter lags. Increase risk of CBM persists throughout the 30 lags for extreme cold while the risk of CBM due to heat is lower and non-significant after 10 days lag. The findings in this study are consistent with previous studies (Martens 1998); the effects of hot and cold temperatures on mortality were immediate (lag 0 ) and longer for cold effect (Pattenden et al. 2003).

We have also studied the association between lag days and mortality risks of incremental cumulative hot and cold temperature effects. The results suggest that there is a severe risk $(\mathrm{RR}=2.09,95 \%$ CI $1.74 ; 2.51)$ of mortality for a 30-daycumulative exposure to extreme cold temperatures of $7.3^{\circ} \mathrm{C}$. Similarly, the cumulative effect of a 30-day exposure to an extreme hot temperature of $30{ }^{\circ} \mathrm{C}$ is $52 \%$ higher than sameday exposure. Various underlying mechanisms have been
Fig. 6 Cumulative relative risk of CBM associated with temperature in the lag periods $0-30$ and $0-35$. The figure presents the cumulative exposure-response curves (a) and lag-response curves (b), for models 1 and 6 for lags $0-30$ and $0-35$ with $13 \mathrm{dfs} /$ year at $5{ }^{\circ} \mathrm{C}$ with reference at minimum mortality temperature (MMT) of $22^{\circ} \mathrm{C}$
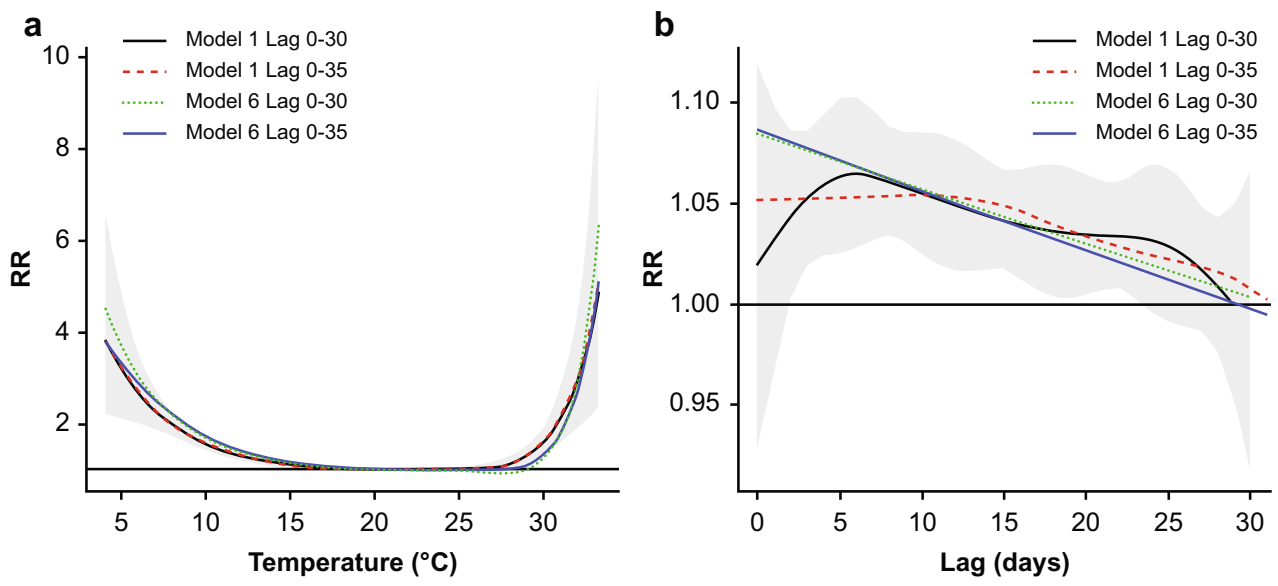
proposed to explain the mortality risk associated with exposure to heat and cold. Exposure to high temperatures might cause dehydration, reductions in cerebral perfusion, sweating thresholds, and increased surface blood circulation (Chen et al. 2016; García-Trabanino et al. 2015; Keatinge et al. 1986). These influences might cause or trigger death from cerebral thrombosis (García-Trabanino et al. 2015). Exposure to lower temperatures has been associated with increased heart rate via affecting factors such as cholesterol and fibrinogen, peripheral vasoconstriction and plasma fibrinogen concentrations, and increased blood viscosity that increases the likelihood of death (Keatinge et al. 1984; Wilson et al. 2011; Woodhouse et al. 1994). The immediate increase of deaths after a decrease in temperature could be explained by changes in blood pressure that cause oxygen deficiency in the heart muscle as well the increased risk of thrombosis (Ballester et al. 1997).

An interesting finding is that cerebrovascular disease is significantly associated with seasonality; there is higher likelihood of mortality from cerebrovascular in the winter than in the summer. Our findings are consistent with a number of previous studies in Macedonia (Kendrovski 2006), Rússia (Revich and Shaposhnikov 2008) and Thailand (Vajanapoom et al. 2001).

We acknowledge the following limitations in our study. Firstly, temperature exposure was not measured at the individual level. Secondly, the mortality outcomes did not account for age, gender, presence of chronic diseases, and socio-economic factors. Those factors could modify the exposure-response relationship between temperature and mortality. Thirdly, this study was confined to one District, which makes our results hard to be generalized to others regions of Portugal. Lastly, the smoothing methods for exposure-lag-response relationships are difficult to validate in DLNM (Gasparrini et al. 2017). We explored quadratic B-spline and linear function each separately for exposure-response and lag-response. These limitations do not reduce the importance of the findings from this study. The findings provide detailed assessment of temperature-cerebrovascular mortality in hot and cold temperature in Lisbon.

\section{Conclusions}

The present study shows a non-linear pattern between mean temperature and the number of deaths, showing an overall U-shape and revealing a comfort zone for intermediate temperatures. The study allows us to conclude that cerebrovascular mortality has gradually diminished over the period under analysis. This fact is consistent with other studies conducted in Sweden (Åström et al. 2013), South Korea (Xu et al. 2013), and Spain (Lee et al. 2016). In our study, several reasons may be responsible for this decline, namely the improvement in the indicators of this cause of death (Cayuela et al. 2016), the introduction of preventive measures (DGS - Direção Geral de Saúde 2015), and the strategic programs included in the National Health Plan, measures that were implemented during the period under analysis. The dissemination of the Contingency Plans for Heat (DGS - Direção Geral de Saúde 2014) and Winter (DGS - Direção Geral de Saúde 2016) by the Portuguese Directorate-General of Health, was providing information to minimize one's risk of exposure to extreme temperatures.

In conclusion, the probability of dying from cerebrovascular disease in Lisbon was higher in winter than in summer. Therefore, our study suggests that the effect of cold and heat should not be underestimated. Anticipation of temperaturerelated mortality, under future warming scenarios, including demographic changes and adaptation, may constitute a priority for Public Health in Portugal.

Acknowledgements The authors would like to thank the Portuguese National Statistics Institute - Statistics Portugal for its support with obtaining the health data from this database. Mónica Rodrigues and Paula Santana are members of CEGOT, Research Centre on Geography and Spatial Planning, that is supported by the European Regional Development Funds, through the COMPETE 2020 - Operational Programme 'Competitiveness and Internationalization', under Grant POCI-01-0145- FEDER-006891; and by National Funds through the Portuguese Foundation for Science and Technology (FCT) under Grant $\mathrm{UID} / \mathrm{GEO} / 04084 / 2013$. The funders had no role in study design, data collection, data analysis, data interpretation, or writing of the manuscript.

\section{Compliance with ethical standards}

Conflict of interest The authors declare that they have no competing interests.

\section{References}

Anderson BG, Bell ML (2009) Weather-related mortality: how heat, cold, and heat waves affect mortality in the United States. Epidemiology 20:205-213. https://doi.org/10.1097/EDE.0b013e318190ee08

Antunes L, Silva S, Marques J et al (2017) The effect of extreme cold temperatures on the risk of death in the two major Portuguese cities. Int J Biometeorol 61:127-135. https://doi.org/10.1007/s00484-0161196-X

Armstrong B (2006) Models for the relationship between ambient temperature and daily mortality. Epidemiology 17:624-631. https://doi. org/10.1097/01.ede.0000239732.50999.8f

Åström D, Forsberg B, Edvinsson S et al (2013) Acute fatal effects of short-lasting extreme temperatures in Stockholm, Sweden: evidence across a century of change. Epidemiology 24:820-829. https://doi. org/10.1097/01.ede.0000434530.62353.0b

Ballester F, Corella D, Pérez-Hoyos S et al (1997) Mortality as a function of temperature. A study in Valencia, Spain, 1991-1993. Int J Epidemiol 26:551-561

Braga AL, Zanobetti A, Schwartz J (2001) The time course of weatherrelated deaths. Epidemiology 12:662-667

Cayuela A, Cayuela L, Escudero-Martinez I et al (2016) Análisis de las tendencias en la mortalidade por enfermedades cerebrovasculares en 
Espanã 1980-2011. Neurología 31:370-378. https://doi.org/10. 1016/j.nrl.2014.09.002

Chen H, Wang J, Li Q, Yagouti A, Lavigne E, Foty R, Burnett RT, Villeneuve PJ, Cakmak S, Copes R (2016) Assessment of the effect of cold and hot temperatures on mortality in Ontario, Canada: a population-based study. CMAJ Open 4:E48-E58. https://doi.org/ 10.9778/cmajo.20150111

Curriero FC, Heiner KS, Samet JM, Zeger SL, Strug L, Patz JA (2002) Temperature and mortality in 11 cities of the eastern United States. Am J Epidemiol 155:80-87. https://doi.org/10.1093/aje/155.1.80

Davis RE, McGregor GR, Enfield K (2016) Humidity: a review and primer on atmospheric moisture and human health. Environ Res 144:106-116. https://doi.org/10.1016/j.envres.2015.10.014

DGS - Direção Geral de Saúde (2015) Doenças Cérebro-vasculares em Números - Programa Nacional para as Doenças Cérebro-vasculares. https://www.dgs.pt/em-destaque/portugal-doencas-cerebrocardiovasculares-em-numeros-201511.aspx. Accessed 18 May 2017

DGS - Direção Geral de Saúde (2014) Plano de Contingência para Temperaturas Extremas Adversas - Módulo de Calor 2014. https:// www.dgs.pt/documentos-e-publicacoes/plano-de-contingenciapara-temperaturas-extremas-adversas-modulo-calor-2014.aspx. Accessed 18 May 2017

DGS - Direção Geral de Saúde (2016) Plano de contingência para temperaturas extremas adversas - Módulo inverno. https://www. dgs.pt/documentos-e-publicacoes/saude-sazonal-inverno-saude-. aspx. Accessed 18 May 2017

Dominici F, Samet JM, Zeger SL (2000) Combining evidence on air pollution and daily mortality from the 20 largest US cities: a hierarchical modelling strategy. J R Stat Soc A 163:263-302. https://doi. org/10.1111/1467-985X.00170

Dormann CF, Elith J, Bacher S, Buchmann C, Carl G, Carré G, Marquéz JRG, Gruber B, Lafourcade B, Leitão PJ, Münkemüller T, McClean C, Osborne PE, Reineking B, Schröder B, Skidmore AK, Zurell D, Lautenbach S (2013) Collinearity: a review of methods to deal with it and a simulation study evaluating their performance. Ecography 36:27-46. https://doi.org/10.1111/j.1600-0587.2012.07348.x

Eng H, Mercer JB (1998) Seasonal variations in mortality caused by cardiovascular diseases in Norway and Ireland. J Cardiovasc Risk 5:89-95

García-Trabanino R, Jarquín E, Wesseling C, Johnson RJ, GonzálezQuiroz M, Weiss I, Glaser J, José Vindell J, Stockfelt L, Roncal C, Harra T, Barregard L (2015) Heat stress, dehydration, and kidney function in sugarcane cutters in El Salvador - a cross-shift study of workers at risk of Mesoamerican nephropathy. Environ Res 142: 746-755. https://doi.org/10.1016/j.envres.2015.07.007

Gasparrini A (2014) Modeling exposure-lag-response associations with distributed lag non-linear models. Stat Med 33:881-899

Gasparrini A, Guo Y, Hashizume M, Lavigne E, Zanobetti A, Schwartz J, Tobias A, Tong S, Rocklöv J, Forsberg B, Leone M, de Sario M, Bell ML, Guo YLL, Wu CF, Kan H, Yi SM, de Sousa Zanotti Stagliorio Coelho M, Saldiva PHN, Honda Y, Kim H, Armstrong B (2015a) Mortality risk attributable to high and low ambient temperature: a multicountry observational study. Lancet 386:369-375. https://doi.org/10.1016/S0140-6736(14)62114-0

Gasparrini A, Guo Y, Hashizume M, Kinney PL, Petkova EP, Lavigne E, Zanobetti A, Schwartz JD, Tobias A, Leone M, Tong S, Honda Y, Kim H, Armstrong BG (2015b) Temporal variation in heat-mortality associations: a multicountry study. Environ Health Perspect 123: 1200-1207. https://doi.org/10.1289/ehp.1409070

Gasparrini A, Armstrong B, Kenward MG (2010) Distributed lag linear and non-linear models. Stat Med 29:2224-2234. https://doi.org/10. 1002/sim. 3940

Gasparrini A, Guo Y, Sera F, Vicedo-Cabrera AM, Huber V, Tong S, de Sousa Zanotti Stagliorio Coelho M, Nascimento Saldiva PH, Lavigne E, Matus Correa P, Valdes Ortega N, Kan H, Osorio S,
Kyselý J, Urban A, Jaakkola JJK, Ryti NRI, Pascal M, Goodman PG, Zeka A, Michelozzi P, Scortichini M, Hashizume M, Honda Y, Hurtado-Diaz M, Cesar Cruz J, Seposo X, Kim H, Tobias A, Iñiguez C, Forsberg B, Åström DO, Ragettli MS, Guo YL, Wu CF, Zanobetti A, Schwartz J, Bell ML, Dang TN, van DD, Heaviside C, Vardoulakis S, Hajat S, Haines A, Armstrong B (2017) Projections of temperature-related excess mortality under climate change scenarios. Lancet Planetary Health 1:e360-e367

Goodman PG, Dockery DW, Clancy L (2004) Cause-specific mortality and the extended effects of particulate pollution and temperature exposure. Environ Health Perspect 112:179-185. https://doi.org/ 10.1289/ehp.6451

Guo Y, Barnett AG, Pan X, Yu W, Tong S (2011) The impact of temperature on mortality in Tianjin, China: a case crossover design with a distributed lag nonlinear model. Environ Health Perspect 119:1719 1725. https://doi.org/10.1289/ehp.1103598

Keating WR, Donaldson GC (1997) Cold exposure and winter mortality from ischaemic heart disease, cerebrovascular disease, respiratory disease, and all causes in warm and cold regions of Europe. The Eurowinter Group Lancet 349:1341-1346. https://doi.org/10.1016/ S0140-6736(96)12338-2

Keatinge WR, Coleshaw SR, Cotter F, Mattock M, Murphy M, Chelliah $\mathrm{R}$ (1984) Increases in platelet and red cell counts, blood viscosity, and arterial pressure during mild surface cooling: factors in mortality from coronary and cerebral thrombosis in winter. Br Med J (Clin Res Ed) 289:1405-1408

Keatinge WR, Coleshaw SR, Easton JC et al (1986) Increased platelet and red cell counts, blood viscosity, and plasma cholesterol levels during heat stress, and mortality from coronary and cerebral thrombosis. Am J Med 81:795-800

Kendrovski D (2006) The impact of ambient temperature on mortality among the urban population in Skoplje, Macedonia during the period 1996-200. BMC Public Health 6(44). https://doi.org/10.1186/ $1471-2458-6-44$

Lawrence MG (2005) The relationship between relative humidity and the dewpoint temperature in moist air - a simple conversion and applications. Bull Am Meteorol Soc 86:225-234. https://doi.org/10. 1175/BAMS-86-2-225

Lee SW, Kim HC, Lee HS, Suh I (2016) Thirty-year trends in mortality from cerebrovascular diseases in Korea. Korean Circ J 46:507-514. https://doi.org/10.4070/kcj.2016.46.4.507

Martens WJ (1998) Health impacts of climate change and ozone depletion: an ecoepidemiologic modeling approach. Environ Health Perspect 106:241-251. https://doi.org/10.1289/ehp.98106s1241

Näyhä S (2005) Environmental temperature and mortality. Int J Circumpolar Health 64:451-458. https://doi.org/10.3402/ijch. v64i5.18026

Pattenden S, Nikiforov B, Armstrong BG (2003) Mortality and temperature in Sofia and London. J Epidemiol Community Health 57:628 633. https://doi.org/10.1136/jech.57.8.628

Patz JA, Engelberg D, Last J (2010) The effects of changing weather on public health. Annu Rev Public Health 21:271-307. https://doi.org/ 10.1146/annurev.publhealth.21.1.271

Revich B, Shaposhnikov D (2008) Temperature-induced excess mortality in Moscow, Russia. Int J Biometeorol 52:367-374. https://doi.org/ 10.1007/s00484-007-0131-6

Schwartz J, Toulouni G, Bacharova L et al (1996) Methodological issues in studies of air pollution and daily counts of deaths or hospital admissions. J Epidemiol Community Health 50:S3-S11

Vajanapoom N, Shy CM, Neas LM et al (2001) Estimation of particulate matter from visibility in Bangkok, Thailand. J Expo Anal Environ Epidemiol 11:97-102

Vasconcelos J, Freire E, Almendra R, Silva GL, Santana P (2013) The impact of winter cold weather on acute myocardial infarctions in Portugal. Environ Pollut 183:14-18. https://doi.org/10.1016/j. envpol.2013.01.037 
Wilson L, Black DA, Veitch C (2011) Heatwaves and the elderly: the role of the GP in reducing morbidity. Aust Fam Physician 40: $637-640$

Woodhouse PR, Khaw KT, Plummer M, Meade TW, Foley A (1994) Seasonal variations of plasma fibrinogen and factor VII activity in the elderly: winter infections and death from cardiovascular disease. Lancet 343:435-439

Xu B, Liu H, Su N, Kong G, Bao X, Li J, Wang J, Li Y, Ma X, Zhang J, Yu GP, Zhao L (2013) Association between winter season and risk of death from cardiovascular diseases: a study in more than half a million inpatients in Beijing, China. BMC Cardiovasc Disord 13(93). https://doi.org/10.1186/1471-2261-13-93

Yu W, Hu W, Mengersen KL, Guo Y, Pan X, Connell D, Tong S (2011)

Time course of temperature effects on cardiovascular mortality in Brisbane, Australia. Heart 97:1089-1093. https://doi.org/10.1136/ hrt.2010.217166

Yu W, Vaneckova P, Mengersen K, Pan X, Tong S (2010) Is the association between temperature and mortality modified by age, gender and socio-economic status? Sci Total Environ 408:3513-3518. https://doi.org/10.1016/j.scitotenv.2010.04.058 